\title{
IoT Connectivity Standards: How Adaptive is the Current SEP Regulatory Framework?
}

\author{
Beatriz Conde Gallego $\cdot$ Josef Drexl
}

Published online: 20 December 2018

(C) The Author(s) 2018

\begin{abstract}
The Internet of Things is advancing as a new technological paradigm with enormous economic and societal implications. Network connectivity provides the basis. With this in mind, past and current conflicts surrounding the licensing and enforcement of standard essential patents (SEPs) in the information and communications technology (ICT) sector cast a shadow over IoT development. Focusing on the European approach based on competition law, this article explores the extent to which the existing legal framework, which has been mainly developed against the backdrop of problems in the mobile industry, will be capable of responding adequately to the challenges raised by the IoT.
\end{abstract}

Keywords Internet of Things - Standard essential patents - Abuse of market dominance $\cdot$ Lock-in · Patent hold-up · Prohibitory injunctions

B. Conde Gallego $(\bowtie)$

Dr. jur., LL.M. (Würzburg); Senior Research Fellow, Max Planck Institute for Innovation and

Competition, Munich, Germany

e-mail: beatriz.conde@ip.mpg.de

J. Drexl

Dr. jur., LL.M. (UC Berkeley), Professor of Law, Director of the Max Planck Institute for Innovation and Competition, Munich, Germany

e-mail: josef.drexl@ip.mpg.de

J. Drexl

Honorary Professor at the Ludwig-Maximilians-Universität Munich, Munich, Germany 


\section{Introduction}

The Internet of Things (IoT) represents a new technological paradigm with large economic and societal implications. It is estimated that the IoT could reach a level of US\$ 4-11 trillion in global economic value per year by $2025 .{ }^{1}$ Beyond this, the IoT has the potential to become a real game-changer for the attainment of sustainability goals as it can significantly contribute to optimizing energy usage, food production and supply as well as healthcare among others. ${ }^{2}$ Despite the global hype surrounding the IoT, it has no single definition. In an attempt to point out the common aspects of the multiple definitions, the Internet Society ${ }^{3}$ uses the term where network connectivity and computing capability extend to objects, sensors and everyday items, allowing these devices to collect and exchange data with minimal human intervention. ${ }^{4}$ Network connectivity thus provides the foundation of the IoT. With this fact in mind, past and current conflicts surrounding the licensing and enforcement of standard essential patents (SEPs) in the information and communications technology (ICT) sector cast a shadow over IoT development. The increased need for connectivity together with the involvement of new market players alien to the ICT sector certainly suggest that the IoT could be the next field for future patent wars. ${ }^{5}$ Aware of this risk, the European Commission published a Communication in November 2017 where it sets out key principles for a balanced and predictable framework for SEPs. ${ }^{6}$

This article aims to explore the extent to which the existing legal framework which has been mainly developed against the backdrop of problems in the mobile industry will be capable of responding adequately to the challenges raised by the IoT. Its focus is thereby the European approach based on competition law. In July 2015, the Court of Justice of the European Union (CJEU) handed down its judgment in Huawei v. ZTE ${ }^{7}$ and confirmed the general applicability of Art. 102 of the Treaty on the Functioning of the European Union (TFEU) to the conduct of a dominant SEP holder seeking an action for prohibitory injunction against a licensee willing to conclude a licence on fair, reasonable and non-discriminatory (FRAND) terms. Moreover, the CJEU utilised EU competition law as a legal basis for designing a framework for the FRAND negotiation processes. As this article will show, the Huawei judgment has to be regarded as an off-spring of the "old" era characterised by disputes among competing companies in the telecommunications sector and limited to the use of mobile devices by humans. The Huawei judgment may well be in need of modification and further evolution to adequately respond to the more complex and varied circumstances of IoT conflicts.

\footnotetext{
1 McKinsey Global Institute (2015), p. 35.

2 World Economic Forum (2018), p. 3.

3 The Internet Society is a US American nonprofit organisation founded in 1992 to provide leadership in Internet-related standards, education and policy.

${ }^{4}$ Rose et al. (2015), p. 17.

5 See e.g. Pepe et al. (2018).

6 European Commission (2017a), p. 2.

7 CJEU, Case C-170/13, Huawei Technologies (16 July 2015) EU:C:2015:477.
} 
The structure of this article is as follows. Section 2 sets the stage by working out the IoT-specific technological factors impacting the SEP regulatory framework and giving an overview of IoT connectivity technologies. Building on this analysis, Sect. 3 examines the extent to which market dominance - the element which opens up the application of Art. 102 TFEU - can be established in the market for IoT connectivity technologies. Section 4 then looks at the principles and the licensing negotiation framework established in the Huawei judgment and assesses their soundness for disputes arising in the IoT context. Section 5 provides conclusions.

\section{Connectivity in the IoT}

\subsection{General Considerations}

The success of the IoT depends on devices capable of connecting with each other and the Internet. Connectivity-related technologies and standards enabling interoperability in this field are therefore of utmost importance. This fact alone, however, does not distinguish the IoT from more traditional telecommunications applications such as mobile telephony. Yet the IoT is distinct in at least two ways. First, connectivity becomes ubiquitous, not only in quantitative and spatial terms, but most importantly with respect to the vast number of economic sectors that will rely on it. From agriculture to energy and utilities, industrial manufacturing, transportation, consumer electronics, retail, healthcare, finance and insurance or the public sector, IoT-related products and services will be offered in just about every sector of the economy. As a consequence, an increasing number of economic actors for which network connectivity has traditionally played no or only a marginal role in their business models will in the future hinge on it.

Secondly, uses for which connectivity is needed in the IoT context are extremely varied and differ substantially from traditional voice and data services. For example, connected thermostats in residential and commercial buildings can, based on the data they gather on temperature, humidity and motion, detect when a room is unoccupied and automatically adjust the heating or cooling and lights to reduce energy use. In the area of connected cars, to give another example, ${ }^{8}$ realtime data sent from the car can be used to improve traffic efficiency (e.g. by notifying users of traffic jams), road safety (e.g. by alerting dangerous road conditions or an immediate collision) and driving experience (e.g. by indicating the nearest fuel station or available parking spaces). Likewise, sensor data from the car can provide the base for after-sales services as well as for accurate car insurance estimates.

Each IoT use case poses its own requirements for connectivity in terms of coverage, data rate, latency and energy efficiency. ${ }^{9}$ To stay with the examples

\footnotetext{
${ }^{8}$ For a comprehensive overview of current and future use cases for IoT technologies see McKinsey Global Institute (2015), pp. 36 et seq.

9 See Northstream (2016), pp. 4-9 (analysing the technical, commercial and ecosystem-related considerations that influence the choice of a connectivity technology for different use cases).
} 
above, for IoT applications ${ }^{10}$ building on the data gathered by smart thermostats, good indoor coverage over short distances and battery longevity will be key technological requirements. In contrast, data rate and latency will be less important concerns since data volumes will be generally small and communications rather infrequent and capable of tolerating delay. Connected cars, on the other hand, will have a need for highly reliable wide-area coverage and, as they evolve into fully automated cars, for extremely low latency connectivity. In addition, for applications providing infotainment services, high data throughput will be crucial. Given this wide range of IoT connectivity demands and the need in many cases to make tradeoffs between conflicting technical requirements, there will hardly be a single technology suitable to serve all IoT use cases in all markets. ${ }^{11}$

\subsection{IoT Connectivity Technologies}

Indeed, the economic potential offered by the IoT together with its specific connectivity needs has fostered the development of already existing and new connectivity technologies. As a result, there have never been as many connectivity options as there are today. ${ }^{12}$

Traditional cellular technologies, which mainly comprise the GMS/GPRS/EDGE $(2 \mathrm{G})$, UMTS/HSPA (3G) and LTE (4G) radio access technologies, standardised under the auspices of the 3rd Generation Partnership Project (3GPP), are the leading technologies for wireless communication worldwide. Their global coverage together with their high-quality service make them suitable to serve very demanding IoT applications requiring high data rates, high reliability and low latency. Yet their connectivity capabilities exceed the requirements of many IoT use cases. Moreover, $3 \mathrm{G}$ and $4 \mathrm{G}$ connectivity modules are particularly power hungry and expensive. In order to address the needs of low-end IoT applications ${ }^{13}$ for low power consumption, low-cost devices and small data transmission, two developments have occurred in parallel. On the one hand, Low Power Wide Area (LPWA) technologies have emerged as a novel technology category for the IoT. Operating in the unlicensed spectrum, LPWA technologies offer low-power, wide-area connectivity to a massive number of devices distributed over large geographical areas at significantly lower cost. Among the different LPWA technologies currently present in the market, Sigfox and LoRa have emerged as the leaders. ${ }^{14}$ On the other hand, attracted by the huge market opportunity of LPWA networks and forced by the rapid expansion of LPWA technologies in the unlicensed spectrum, the mobile industry has worked intensively to adapt the existing cellular technologies to the necessities

\footnotetext{
10 The terms "IoT application" and "IoT use case" are largely used interchangeably in the literature to describe specific instances wherein a technological solution is brought to practical use within a given area.

11 Northstream (2016), p. 8.

12 For an overview see Ryberg (2018), pp. 3-16.

13 These include for instance metering and monitoring applications in a great number of areas such as utilities, manufacturing, agriculture, building automation or smart cities. In fact, low-end IoT applications account for the vast majority of current IoT applications.

14 Ryberg (2018), p. 11.
} 
of the IoT. ${ }^{15}$ In record time, the $3 \mathrm{GPP}$ has produced a new category of standards for machine-type communication. ${ }^{16}$ Two of them represent IoT-related enhancements to the $4 \mathrm{G}$ standard, namely, the Long Term Evolution for Machines (LTE-M, officially eMTC) and the Narrowband Internet of Things (NB-IoT). The third technology, Enhanced Coverage-GSM-IoT (EC-GSM-IoT), is an evolution of the $2 \mathrm{G}$ standard and is thus likely to be implemented in countries with insufficient $4 \mathrm{G}$ coverage.

In addition to these wide-range technologies, multiple connectivity solutions also exist in the short-range area. Covering transmission distances up to approximately 100 meters, short-range technologies are commonly deployed in the home, building and industrial automation and the wearables fields as well as in different applications in smart city environments. While the most well-known among them are probably Wireless-Fidelity (Wi-Fi) and Bluetooth, ${ }^{17}$ at least four other technologies - Zigbee, Z-Wave, Thread and WirelessHART - compete in these areas. $^{18}$

\subsection{Competitive Dynamics}

From this short overview of the current IoT technological landscape, and in sharp contrast to the smartphone market, it follows that the technological path for IoT connectivity is far from obvious. To be sure, traditional cellular connectivity in its different flavours and generations will be the most suitable and probably the only connectivity solution for a significant number of IoT applications. In particular, mission critical applications - first and foremost for automated mobility, ${ }^{19}$ but also other use cases such as remote surgery or industrial automation for which failure is no option - will only be supported by the connectivity capabilities of future cellular technologies (i.e. 5G). For the vast bulk of IoT use cases, however, alternative technologies exist and compete intensively for implementation.

The LPWA area is at present the most contested one with two main battles being fought, on the one hand between non-cellular LPWA technologies and the newly introduced cellular IoT standards, ${ }^{20}$ and on the other among different cellular IoT standards. Benefitting from their first-mover advantages, non-cellular LPWA technologies have already attained extensive market presence. At the same time, cellular LPWA technologies are rapidly entering the market basically due to the fact that they are able to capitalise on existing infrastructure. Within five years, the

\footnotetext{
15 Due to these developments, the term LPWA is increasingly used to comprise both non-cellular and cellular technologies.

16 For more technical details see GSMA (2016).

17 Both, Wi-Fi and Bluetooth have been adapted for the IoT. The new Wi-Fi HaLow standard was published in 2017 and is now suited to small data packages and power-optimised devices while providing transmission ranges up to $1 \mathrm{~km}$. Bluetooth Low Energy (BLE) has been designed for low-power devices that need to run for long periods on small batteries.

18 Lethaby (2017), pp. 7 et seq.

19 As an example, see the importance of interconnectivity and cellular technology as the technological backbone of automated road traffic recognised by European Commission (2018), pp. 11-12.

${ }^{20}$ LTE-M, NB-IoT and EC-GSM-IoT, as mentioned at Sect. 2.2 above.
} 
number of cellular LPWA connections is expected to be comparable with that of noncellular LPWA connections. ${ }^{21}$ Which of the cellular IoT technologies will gain more market traction is still uncertain. China will surely have a significant impact on the cellular LPWA market. Not only does the demand for a technology in the world's most populous nation create the necessary volume to achieve a competitive edge on a global scale, the Chinese government has also officially endorsed the NB-IoT standard, the first international telecommunications standard in whose development Chinese companies - with Huawei at the forefront - have been intensively involved. Meanwhile, all three Chinese telecom operators are heavily investing in its deployment in order to reach the ambitious targets set by the government. ${ }^{22}$

As mentioned above, competition is also strong in the short-range area, with the home and building automation space being the most contested. In addition to this, short-range technologies are increasingly targeting IoT markets beyond the consumer space. Technologies like Wi-Fi and Bluetooth have significantly lowered power consumption and expanded their capabilities to cover wider areas. Thanks to their other unique advantages such as wider availability and greater brand awareness, low chip costs and strong presence in devices like smartphones, they are now becoming an important connectivity option in the utilities and transportation sectors as well as in smart cities, thus blurring the boundaries between the wideand short-range area connectivity categories.

In the middle to long term, strong competition will certainly result in a consolidation of the currently fragmented IoT technology landscape. Still, alternative technologies will continue to exist. Various arguments support this conclusion. First, the IoT with its multiple use cases, each with its own connectivity requirements, is far too diverse for a single connectivity technology to serve them all. Whereas different technologies will certainly address specific groups of use cases, overlaps will be inevitable. Moreover, from a technological perspective, it will be feasible for connectivity providers to offer different connectivity options. Some telecom operators are already deploying both non-cellular and cellular LPWA networks. Likewise, device manufactures may consider supporting different technologies to enlarge their sales markets as companies will face situations where multiple technologies need to be used in parallel, either because they serve different applications that are part of a larger system, or because they serve the same application but in different environments or geographies. ${ }^{23}$ Lastly, work being done at the upper - data-related - levels of the IoT points at a trend towards connectivity agnostic platforms, which enable the exchange and sharing of data between different applications irrespective of the underlying connectivity solution. ${ }^{24}$ Also, the adoption of $5 \mathrm{G}$ as the next generation of telecommunications standards will not fundamentally change this conclusion. As stated above, 5G will have a truly enabling nature for those IoT applications requiring ultra-reliable communications.

\footnotetext{
21 See ABI Research (2018).

22 For more details on the developments in China see Ryberg (2018), pp. 109 et seq. and Huang (2018), p. 1 et seq.

23 See Northstream (2016), p. 16.

24 This is for example the case of the oneM2M reference architecture, see oneM2M (2017), pp. 2 et seq.
} 
For other IoT applications, however, $5 \mathrm{G}$ is neither an imperative, since existing connectivity solutions already serve such use cases well, nor will it be as revolutionary as it is thought to be because the current NB-IoT and LTE-M standards are expected to fulfil the $5 \mathrm{G}$ requirements for massive machine-type communications. $^{25}$

\section{Market Dominance in the IoT}

\subsection{SEP Ownership and Market Dominance}

Among the entire set of issues that SEPs raise, the question concerning the relationship between SEP ownership and market power has so far probably been one of the less contested issues. This is somewhat remarkable since the existence of market dominance on the part of an SEP holder is a precondition to control the SEP owner's conduct under competition rules, specifically under Art. 102 TFEU. It is widely recognised that mere ownership of an intellectual property (IP) right and a patent in particular does not confer a dominant position. ${ }^{26}$ This being the general principle, it is also acknowledged that in certain circumstances an IP right can nonetheless be capable of creating such a position. ${ }^{27}$

SEPs are different from other kinds of patents in the sense that if they are valid and truly standard essential, their use is unavoidable to implement standardcompliant products or services. In his opinion in the Huawei case, Advocate General Wathelet proposed the establishment of a rebuttable presumption that the owner of an SEP holds a dominant position. ${ }^{28}$ While his argumentation rather focused on the need to conduct a case-by-case analysis on this question, he implicitly suggested that there is a certain direct relationship between SEP ownership and market dominance. Indeed, court rulings on SEP cases have largely affirmed the existence of a dominant position. ${ }^{29}$ In doing so, they have basically followed two different approaches to define the relevant market. On the one hand, relying on the European Commission's decision in Motorola, ${ }^{30}$ Birss $\mathrm{J}$ in the Unwired Planet judgment of

\footnotetext{
25 See GSMA (2018), pp. 7 et seq.

${ }^{26}$ CJEU, Joint Cases C-241/91 P and C-242/91 P, RTE and ITP v. Commission ("Magill") (6 April 1995) EU:C:1995:98, para. 46.

${ }^{27}$ CJEU, Case C-457/10 P, AstraZeneca v. Commission (6 December 2012) ECLI:EU:C:2012:770, para. 186.

28 AG Wathelet, Case C-170/13, Huawei Technologies (20 November 2014) ECLI:EU:C:2014:2391, para. 58. This approach was most recently followed by the Court of Appeal of England and Wales. See Unwired Planet International Ltd et al v. Huawei Technologies Co Ltd [2018] EWCA Civ 2344, paras. 226-227.

${ }^{29}$ In most cases, however, the question of market dominance has either not been contested or just superficially addressed by the courts; see Picht (2017), p. 877. In the Huawei case, the fact that Huawei was dominant with its SEP for which it sought injunctive relief was not disputed among the parties. Hence, the CJEU was not required to provide its view on how to assess market dominance in such cases. See CJEU, Case C-170/13, Huawei Technologies, EU:C:2015:477, para. 28.

${ }^{30}$ European Commission Decision of 29 April 2014, Case AT. 39985 - Motorola - Enforcement of GPRS Standard Essential Patents.
} 
the High Court of England and Wales identified the market for licensing each SEP individually as a separate product market. In this market, the SEP holder has a $100 \%$ market share. ${ }^{31}$ On the other hand, German courts have mainly considered the market for standard-compliant products to be the market in which competition is restricted. Accordingly, the owner of an SEP holds a dominant position in those situations where only products that comply with the standard and thus implement the SEP can effectively compete in it. $^{32}$

By referring to the need to offer standard-compliant products in order to effectively compete in the market, this later line of reasoning comes to the central point. Hence, it is not the standard essentiality of a patent, but the "market essentiality" of a standard which is crucial to conclude that an SEP owner holds a dominant position. The European Commission stressed this aspect expressly in its analysis of the relevant market and the assessment of dominance in the Motorola decision. Departing from the general principles set out in its different communications, ${ }^{33}$ the Commission concentrated in this case on the technology market as the market encompassing the technology incorporating the disputed SEP and its close substitutes, i.e. other technologies and related IP rights which customers could use as alternatives. For this market, the Commission concluded that there were no viable substitutes to the technology (i.e. standard) incorporating Motorola's SEP. ${ }^{34}$ Only in a second step did the Commission go on to consider the standard essentiality of Motorola's patent and decided that the market for its licensing constituted a separate relevant market in which, by definition, Motorola held a $100 \%$ market share. ${ }^{35}$ Whereas the Commission deemed this large market share to be strong evidence for the existence of a dominant position, it nevertheless regarded two other factors to be of particular importance in reaching this conclusion. The first was the fact that due to the widespread adoption of the GPRS standard and the fact that all mobile devices offered in the market implemented it, compliance with the standard was indispensable for manufacturers of mobile devices. ${ }^{36}$ Closely related to this, the Commission pointed to the fact that since alternative standards offering comparable functionalities were unlikely to emerge within a reasonable timeframe, players in the mobile industry were locked into this standard. ${ }^{37}$

Although the Commission's decision focused on a particular standard, namely GPRS, Birss $\mathrm{J}$ in Unwired Planet did not hesitate to apply this later conclusion to

\footnotetext{
${ }^{31}$ Unwired Planet v. Huawei, [2017] EWHC 711 (Pat), paras. 631 and 670.

32 Dusseldorf District Court (Landgericht Düsseldorf) of 19 January 2016, Case 4b O 120/14, Handover Verbesserungsverfahren, para. VII, 6, a.

${ }^{33}$ Commission Notice on the definition of the relevant market for the purpose of Community competition law, [1997] OJ C 372/5, pp. 5-13; Communication from the Commission - Guidelines on the applicability of Article 101 TFEU to horizontal co-operation agreements, [2011] OJ C 11/1, para. 116; Communication from the Commission - Guidelines on the application of Article 101 TFEU to technology transfer agreements, [2014] OJ C 89/3, paras. 20 et seq.

${ }^{34}$ European Commission Decision of 29 April 2014, Case AT. 39985 - Motorola - Enforcement of GPRS Standard Essential Patents, paras. 193 and 212.

35 Ibid., para. 213.

36 Ibid., paras. 227-230.

37 Ibid., paras. 231 et seq.
} 
other wireless telecommunications standards. ${ }^{38}$ In this regard, however, the IoT may substantially differ from the more traditional mobile industry. As shown above, multiple alternative technologies offering connectivity for IoT applications already exist and are expected to continue to exist in the future. ${ }^{39}$ Selecting the most suitable among them is definitely one of the strategic questions which companies implementing IoT projects have to answer in the first place. Technical factors such as coverage and data rate but also the price they will have to pay for connectivity will undoubtedly influence their decision. Certainly, the number of technologies companies may choose from will vary for different IoT use cases. For some IoT applications, the technology market will very much resemble that in the smartphone sector. For many others IoT use cases, however, the relationship between SEP ownership and market dominance will be less straightforward than currently assumed. In this context, the definition of the relevant market and the determination of a dominant position on the part of an SEP holder will be key questions that competition agencies and courts will need to carefully address in individual cases.

\subsection{Lock-in of a Single Implementer}

Whenever connectivity providers and device makers are able to select between different connectivity technologies, the ability of SEP holders to leverage on the standard essentiality of their patents will to a large extent be constrained. Hold-up scenarios, where an SEP holder tries to extract excessive royalties from standard implementers or otherwise to impose on them unreasonable licence conditions may be less common in the IoT than presently feared. Hence, while apparently contradicting the argument that connectivity is a key component of IoT solutions, demand for connectivity - if not in all but in a wide array of IoT application areas will be rather inelastic. As pointed out above, the cost of connectivity will be a decisive factor for companies deploying IoT solutions when deciding which connectivity technology they want to implement. Furthermore, they will face additional costs related to the provision of other IoT services such as the storage, aggregation and analysis of data. ${ }^{40}$

Though being cautious about generalisations, it can be expected that when a choice exists between alternative connectivity options, companies will opt for the one which allows them to extract the highest profit margins. This, in turn, may discipline technology owners as regards their pricing behaviour.

Yet this conclusion presupposes that companies seeking connectivity have a real opportunity to choose among different alternative technologies. This is surely the case if they are in an early phase of the implementation of their IoT projects and can still react to changes in the conditions at which a particular connectivity technology is offered. If, on the contrary, a company has already invested in the implementation

\footnotetext{
38 See Unwired Planet v. Huawei, [2017] EWHC 711 (Pat), para. 640: “[...] The SEPs which have been litigated and found to be essential are essential to 2G/GSM, 3G/UMTS and 4G/LTE. Today's industry is locked into those standards."

39 See particularly Sect. 2.3 above.

${ }^{40}$ Generally on the different building blocks of the IoT see European Commission (2017b), pp. 33 et seq.
} 
of a connectivity technology and has hence incurred sunk costs, the possibility to switch to an alternative technology may be severely restricted. Under these circumstances, this single implementer is locked into this technology in such a way that the technology owner is in a position to impose unreasonable and/or discriminatory licence conditions vis-à-vis this single implementer. In terms of competition law, the question that then arises is whether, in spite of the technology market being competitive, market dominance can be affirmed.

For the purpose of answering this question, a look at the competition law analysis of aftermarkets is helpful. ${ }^{41}$ While acknowledging that an overall "system market" can be defined encompassing both the primary product (e.g. machinery equipment) and the complementary products or services (e.g. spare parts or aftersales services), the European Commission in its decisional practice has consistently considered the primary market and the secondary market as two distinct, separate markets. ${ }^{42}$ The interdependences between these two markets are, however, taken into account when conducting the analysis of dominance. In this context, the Commission proceeds according to a two-step analysis. ${ }^{43}$ First, it looks at the extent to which customers purchasing the primary product make an informed choice between various manufacturers and also consider important factors relative to the secondary product when making this choice. The less this is the case, the more likely it is that dominance in the secondary market may be found. Secondly, it examines the potential reaction of customers in the primary market to an increase in price in the secondary market. The degree of competition in the primary market and the existence of barriers to switch to alternative manufacturers, but also the possibility to discriminate between existing and new customers and the producer's prospects on the primary market are all relevant factors for this analysis.

Whether it is possible in the lock-in scenarios considered in this article to distinguish between a primary and a secondary market, or whether a similar analysis can at least be applied by analogy, ${ }^{44}$ is not that clear. Yet it is possible to distinguish between two separate business decisions to be made by the technology implementer at different stages of implementation. This also raises the question regarding the point in time at which market dominance needs to be assessed.

First, prior to the implementation, the implementer has to choose among different competing connectivity technologies. At this stage, it can be expected that a company that is about to take such a far-reaching decision will carefully consider all relevant factors concerning this technology, including the amount of the entire IP

\footnotetext{
${ }^{41}$ The European Commission's approach and decisional practice to aftermarkets is summarised in OECD (2017).

${ }^{42}$ See European Commission, Rejection Letter of 22 September 1995, Case No. IV/34.330 - Pelikan/ Kyocera, paras. 54-57; Rejection Letter of 7 January 1999, Case No. IV/E2/36.431 - Info-Lab/Ricoh, paras. 19 et seq.

${ }^{43}$ See European Commission, Rejection Letter of 22 September 1995, Case No. IV/34.330 - Pelikan/ Kyocera, paras. 61-68. The Commission's approach has been confirmed by the General Court, Case T-296/09, European Federation of Ink and Ink Cartridge Manufacturers (EFIM) v. Commission (24 November 2011) ECLI:EU:T:2011:693, para. 60.

${ }^{44}$ On the idea to apply the aftermarket analysis to these situations by analogy see Yamaguchi (2018), pp. 49 et seq.
} 
royalties it will have to pay. This being said, it is also true that the implementer is confronted with considerable information problems. Given the fact that FRAND does not convey a specific royalty rate, the final royalties to be paid will only be known once licensing negotiations have been concluded with all owners of patents that are essential for the individual technology. Even where patent owners have already granted licences to third parties, the royalty rates agreed upon will rarely be known to the public due to non-disclosure obligations. ${ }^{45}$ Assuming that such information were available, the commitment not to discriminate between licensees would not impose much constraints on the patent owner's ability to offer different license conditions, as variations can oftentimes be justified by the argument that licensees are not "similarly situated". ${ }^{46}$ The need for variations can be even more easily argued in IoT settings, since devices and use cases can differ considerably. Under these circumstances, the obvious decision for the implementer would be to clear rights ex ante, i.e. prior to implementation of a specific technology. Yet at this point the reasoning of the CJEU in the Huawei judgment comes into the picture. Even if a company can in fact choose between different technologies, the implementation of a single technology can lead to huge uncertainties about which of the many patents declared standard-essential will be needed for manufacturing the concrete devices and whether all SEPs are in fact valid. ${ }^{47}$ In addition, early implementation is also both in the public interest in rapid market dissemination of IoT connectivity and in line with the very purpose of the FRAND commitment scheme implemented by standard development organisations (SDOs). ${ }^{48}$

It is then at the second - ex post - stage, once a particular technology has been implemented, that the implementer seeks licences for the individual patents, or at best, for the patent portfolios of individual rightholders. As a matter of principle, an implementer could still at this stage decide to switch to an alternative technology whenever the patent holder were to enforce its patent and demand excessive royalty rates. Nonetheless, if switching costs are high as is often the case, this decision may be considerably impaired. This shows that competition between different technologies as such will not automatically prevent patent hold-up behaviour. Conversely, eventual hold-up behaviour vis-à-vis a locked-in implementer may negatively impact the willingness of other (future) implementers to choose the same technology. Accordingly, the biggest constraint on the patent owner may indeed come from the impact that a hold-up strategy vis-à-vis single implementers can exercise on market reputation. ${ }^{49}$

\footnotetext{
45 On this see Kathuria and Lai (2018) (concluding that such non-disclosure obligations may commercially be justified).

46 European Commission (2017a), p. 7.

47 Case C-170/13, Huawei Technologies (16 July 2015) EU:C:2015:477, para. 62.

48 A large part of the measures envisioned by the Commission in its Communication on SEPs aim precisely at reducing informational gaps and thus at promoting fast implementation of standardised technologies, see European Commission (2017a), pp. 2 et seq. (on increasing transparency on SEPs exposure) and p. 7 (on patent pools and licensing platforms).

49 On how the European Commission takes this factor into account in aftermarket cases see OECD (2017), p. 7.
} 
Direct application of an aftermarket analysis appears doubtful, since there is no distinguishable primary competitive market for the connectivity technologies, as compared to the "secondary market" in which the individual patents are licensed. While it needs to be applied with caution, the logic of aftermarket theory nevertheless seems to allow for assessing market dominance at the time after implementation. This is also in line with the law under Art. 102 TFEU which requires market dominance at the time of the alleged abusive conduct, i.e. when the patent owner seeks injunctive relief after implementation of the patent.

Taking all this into consideration, it follows that the existence of a dominant position of a technology owner may still be established even though there is competition between different connectivity technologies. A case-by-case analysis considering the various factors impacting on the technology owner's conduct is, however, needed. From a methodological perspective, for the purposes of this article it can remain open whether in those cases a narrow market definition is chosen - i.e. the relevant market being the market for the technology to which the implementer is locked-in - or whether the relevant technology market is more widely defined and the special lock-in situation of the implementer is rather considered at the stage of assessing dominance.

\section{Enforcement of SEPs - The Huawei Judgment in the IoT Context}

The application of Art. 102 TFEU in SEPs cases has centered on the limits that this provision sets on enforcement of SEPs, particularly on the availability of injunctive relief. Such relief is important to protect SEP holders against technology implementers unwilling to conclude a licence agreement on FRAND terms. At the same time, good faith licensees need safeguards against the risk of being threatened by an injunction and being obliged to accept excessive non-FRAND licensing terms. ${ }^{50}$ Trying to strike a balance between these interests, the CJEU in Huawei confirmed that in presence of a FRAND commitment an SEP holder seeking an action for a prohibitory injunction violates Art. 102 TFEU, unless it complies with certain procedural requirements. ${ }^{51}$

As regards the enforcement of SEPs in the IoT context and building on the conclusions gained in the preceding analysis, two different sets of issues need to be examined. First, the question arises whether the theory of harm applied in Huawei adequately reflects the particularities of IoT cases. If the answer were in the negative, the subsequent question would be whether a different theory of harm has to be identified to adequately protect effective competition based on Art. 102 TFEU. Secondly, it has to be answered whether the procedural framework for licensing negotiations set by the CJEU will also work for IoT licensing negotiations or whether it is in need of adaptation. ${ }^{52}$

\footnotetext{
50 See European Commission (2017a), p. 9.

51 CJEU, Case C-170/13, Huawei Technologies (16 July 2015) EU:C:2015:477, paras. 53-67.

52 On both questions see also Yamaguchi (2018).
} 


\subsection{The Relevant Theory of Harm}

\subsubsection{The CJEU's Theory of Harm in Huawei}

When reflecting on the negative effect that a request for a prohibitory injunction by an SEP holder may have on competition, the CJEU points to the fact that by enforcing its SEP the holder "can prevent products manufactured by competitors from appearing or remaining on the market and, thereby, reserve to itself the manufacture of the products in question". 53 Obviously influenced by its previous case law on refusal to license, ${ }^{54}$ in Huawei the CJEU relies on a classical leveraging theory as the relevant theory of harm. Accordingly, SEP-based injunctions raise competition law concerns to the extent they enable vertically integrated SEP owners to dominate the downstream market for products in which the standard becomes implemented. The limitations of the CJEU's reasoning for applying Art. 102 TFEU to cases in which the SEP owner is not vertically integrated have already been addressed in the academic literature. ${ }^{55}$ These shortcomings become even more evident in IoT settings.

Depending on the specific industry structure and the business model chosen, IoT stakeholders seeking connectivity will include hardware and IoT device manufacturers, companies offering different kinds of IoT-related IT services and data-related services as well as companies purchasing IoT-enabled products, either for their own use or for sale to the public. ${ }^{56}$ In most cases, the SEP holder will not compete, or intend to compete, in the relevant downstream product or service markets in which firms seeking access to connectivity are active. If the application of Art. 102 TFEU to requests for injunctive relief were to be confined to those cases raising exclusionary concerns, the practical relevance of competition law for SEP-based disputes in the IoT context would be extremely reduced.

Notwithstanding the CJEU's reasoning, courts have actually also applied the Huawei negotiation framework in disputes between non-practicing entities and manufactures of mobile devices without showing particular concerns about the appropriate theory of harm. ${ }^{57}$ This approach can be justified if Huawei is interpreted as extending to scenarios beyond anticompetitive leveraging. ${ }^{58}$ This reading,

\footnotetext{
53 CJEU, Case C-170/13, Huawei Technologies (16 July 2015) EU:C:2015:477, para. 52.

54 CJEU, Joint Cases C-241/91 P and C-242/91 P, RTE and ITP v. Commission ("Magill") (6 April 1995) EU:C:1995:98; Case C-418/01, IMS Health (29 April 2004) EU:C:2004:257.

55 See e.g. Petit (2017), pp. 301 et seq.

56 See Alsen et al. (2017); Body of European Regulators for Electronic Communications (BEREC) (2016), p. 9.

57 See e.g. Dusseldorf District Court of 3 November 2015, Cases 4a O 93/14 and 4a O 144/14, Sisvel v. Haier; Dusseldorf Court of Appeal (Oberlandesgericht Düsseldorf) orders of 13 January 2016, Cases I-15 U 65/15 and I-15 U 66/15, Sisvel v. Haier; Dusseldorf District Court of 31 March 2016, Case 4a O 73/14, Saint Lawrence Communication GmbH v. Vodafone.

58 Indeed, the wording of the judgment is rather ambivalent. On the one hand, the CJEU explicitly accepts a new set of "exceptional circumstances" beyond the previous case law on refusal to license, without explicitly requiring the exclusion of competition in a secondary market in the description of these circumstances. See Case C-170/13, Huawei Technologies (16 July 2015) EU:C:2015:477, paras. 48-51. Yet, immediately in the following para. 52, the CJEU refers to the risk that, under such circumstances, the
} 
however, is not only difficult to reconcile with the general principle that limitations to IP rights and to their judicial protection need to be sufficiently substantiated. ${ }^{59}$ More importantly, there is the risk that the CJEU could reject the application of Huawei to non-leveraging cases altogether in a future referral case. ${ }^{60}$ Hence, in order to apply Art. 102 TFEU to disputes between companies at different levels on the value chain - as will often occur in an IoT setting - a more convincing theory of harm is needed.

\subsubsection{Alternative Theories of Harm}

To frame the abuse in terms of exploitation is the first, more obvious conclusion. Thus, by relying on its ability to seek a prohibitory injunction, the SEP holder is in a position to impose royalties or licence conditions that the licensee would otherwise not have accepted. This kind of patent hold-up is the quintessence of exploitative conduct. Nonetheless, the CJEU did not pursue this argument at all, and not because it would not have been confronted with it. ${ }^{61}$ The CJEU's reluctance to apply Art. 102(a) TFEU to injunctions on SEPs for which the owner has entered into a FRAND commitment may, on the one hand, be explained by the difficulty to identify an appropriate royalty. On the other hand, it may well reflect both the general unwillingness to impose competition-based restrictions on the patent holders' freedom to determine the level of royalties and the fear that by so doing innovation incentives will be diminished. These arguments deserve full support as far as conventional patents are concerned. In the case of SEPs, however, the basic mechanism underlying the patent system, i.e. the exclusion of competition by imitation to foster competition by substitution, might to a large extent be out of play. Thus, if the standardised technology is indispensable to effectively compete in the market, the SEP holder is not exposed to competition by substitute technologies. Even a superior technology could under these circumstances not prevail in the market, unless it would itself be included in a standard that could replace the former one. Still, interoperability and compatibility needs may even require use of the previous standard technology in the future. SEP owners whose technologies have been included in a standard may thus expect licensing revenue for many years. Furthermore, the SEP owner's dominance is not - or not only - the result of the technological superiority of its invention, but rather due to the decision of an SDO to include it in a given standard. Interfering with an SEP owner's freedom to set the price for its technology and limiting its ability to enforce supra-FRAND royalties appears justified in these cases. ${ }^{62}$

Footnote 58 continued

SEP holder "can prevent products manufactured by competitors from appearing or remaining on the market and, thereby, reserve to itself the manufacture of the products in question".

59 Tsilikas (2017), p. 173.

${ }^{60}$ Ibid., p. 174.

${ }^{61}$ As Petit (2017), p. 302 remarks, the CJEU mentions the question of patent hold-up in its summary of the reference by the Dusseldorf District Court and had been previously mentioned by Advocate General Wathelet, Case C-170/13, Huawei Technologies (20 November 2014) ECLI:EU:C:2014:2391, para. 73.

${ }^{62}$ Justifying a competition law intervention in these cases see also First (2017), pp. 241 et seq. 
Yet there is a better, effects-based theory of harm. This theory does not simply categorise patent hold-up as a price-related exploitative abuse. In fact, competition cases in an innovation environment should primarily be analysed in the light of the impact of the alleged anticompetitive behaviour on dynamic competition and innovation. Competitive conduct also expresses itself in innovation activities that are directed at products that replace existing ones or that will create completely new demand. ${ }^{63}$ This is exactly the case where technology firms compete in the context of a standard setting process, trying to get their technological advances included in the standard, and where manufacturers intend to implement such standards in new and innovative products. The negative effects on innovation are hence twofold. On the one hand, the SEP holder's conduct would have a negative impact on follow-on innovation. Excessive royalties increase the price for implementing the standardised technology and discourage its implementation. On the other hand, the SEP holder would reduce trust in the functioning of standard setting processes as an organised process of innovation in which several competing technology developers participate. This is so, because telecommunications technologies in particular are protected by a large number of SEPs held by several patent holders. Patent hold-up exercised by one SEP holder has therefore the potential of indirectly reducing the income of other SEP holders who are faithful to their FRAND commitments, thereby obstructing their incentives to innovate. Hence, competition law enforcement against patent hold-up not only serves the economic interests of implementers and the public interest in promoting follow-on innovation, it is also a prerequisite of trust of all innovating companies in the working of the FRAND system and the standard-setting process.

These negative effects do not depend on whether the concrete SEP holder is also competing in the secondary market with the implementer. The CJEU phrased the theory of harm far too narrowly to adequately respond to the modern challenges SEPs present for dynamic competition and innovation, although it could have easily addressed them by taking inspiration from both the Commission and the opinion of the Advocate General Wathelet in Huawei.

In the Rambus case, the Commission had actually applied Art. 102 TFEU in a standard-setting context, namely, to the patent ambush exercised by a nonpracticing SEP holder. ${ }^{64}$ In that case, the Commission took the view that Rambus had engaged in intentional deceptive conduct by not disclosing the existence of patents and patent applications relevant to a standard and had abused its dominant position by subsequently claiming royalties that it would not have been able to charge absent its deceptive conduct. ${ }^{65}$ Through its conduct, Rambus had deliberately frustrated the expectations of other participants in the standard-setting process and thereby undermined the confidence in this process, which the Commission

\footnotetext{
63 This is why competition in innovation as a separate form of competition deserves protection even before the emerging products and related markets are identifiable. See Communication from the Commission - Guidelines on the applicability of Article 101 of the Treaty on the Functioning of the European Union to horizontal co-operation agreements, [2011] OJ C 11/1, para. 119. In more detail, see Drexl (2012), pp. 516-522.

64 European Commission, Commitment Decision of 9 December 2009, Case COMP 38.636 - Rambus.

65 Ibid., paras. 27-28.
} 
qualified as a precondition to technical development ${ }^{66}$ and as such as an innovation process in itself. Hence, this case shows that the Commission is willing to intervene and control excessive royalty rates to protect innovation within the context of the standardisation processes. ${ }^{67}$ Thereby, justified by an analysis of the adverse effects of the conduct on innovation, the Commission quite rightly sees no need to require exclusionary conduct against a competitor. In fact, the need for protection of trust in the standard-setting process is even greater in the case of non-practicing entities, which do not compete in downstream product markets. Since their only source of income is the royalty streams deriving from implementers, while not depending on access to the SEPs of others, their incentives to engage in patent hold-up should be higher than those of vertically integrated companies. ${ }^{68}$

The Commission also goes a step further in its Guidelines on Horizontal Cooperation Agreements when considering the prevention of effective access to the standard as a particular form of an "anti-competitive result", 69 without requiring any exclusionary effect on competitors. This position can be explained if one not only conceives the standard-setting process as such as a process of dynamic competition and innovation, but as an integral part of a more comprehensive process of innovation that includes the subsequent implementation of the standard in more complex products in downstream markets.

In the same vein, Advocate General Wathelet recommended going further in protecting dynamic competition and innovation in Huawei than did the CJEU. In particular, Advocate General Wathelet did not limit his analysis to vertically integrated SEP holders and a theory of leveraging of market dominance and exclusion. Nor did he focus on the particular aspect of economic dependence as a result of the FRAND declaration and the standardisation ${ }^{70}$ and the exploitative character of enforcing excessive royalty claims through injunctions. ${ }^{71}$ Rather, he both hinted at the negative impact on the standard-setting process and, more importantly, relied on the "adverse effect on competition to the detriment, in particular, of consumers and the undertakings which have invested in the preparation, adoption and application of the standard". ${ }^{2}$ Thereby, as regards the theory of competitive harm, the Advocate General - albeit in a footnote - addressed the two relevant aspects concerning innovation and dynamic competition. ${ }^{73}$ This approach should be followed by the national courts and of course by the CJEU for

\footnotetext{
66 Ibid., para. 29.

67 Drexl (2011), pp. 219 et seq.

68 See also the distinction of three different groups of members of SSOs in the Communication from the Commission - Guidelines on the applicability of Article 101 of the Treaty on the Functioning of the European Union to horizontal co-operation agreements, [2011] OJ C 11/1, para. 267.

69 Ibid., para. 268.

70 AG Wathelet, Case C-170/13, Huawei Technologies (20 November 2014) ECLI:EU:C:2014:2391, paras. 71 and 73-74.

71 Ibid., para. 73.

72 Ibid., para. 74.

73 Ibid., para. 74 (footnote 51).
} 
defining a theory of harm that justifies competition law control of potential patent hold-up also in the absence of exclusionary concerns.

Whereas the need to protect dynamic competition and innovation pertains to the ICT sector in general, it is even more evident in the IoT context. Here, telecommunications technologies do not only enable new products but also a large variety of data-driven services. The greatest value of the IoT comes from the analysis of data collected by sensors and ultimately from the creation of applications which make use of these data. Data collected by sensors allows consumers to be provided with innovative smart devices and services. For their part, businesses and public entities benefit from this kind of data-related innovation as they can significantly optimise their decision-making and as a result improve efficiency and productivity. Inasmuch as connectivity lies at the base of the IoT, strategic conduct aimed at increasing the price for IoT connectivity would certainly affect innovation negatively in the downstream markets for connected devices and related digital services.

To sum up, Art. 102 TFEU may well have an important role to play in licensing disputes arising in the IoT context. Courts and competition agencies confronted with requests for prohibitory injunctions by SEP holders could choose among different theories of harm to justify its application. Enforcers should not feel restricted by the need to show exclusion, or refrain from applying a theory of exploitative abuse. Yet to avoid welfare-reducing under-enforcement, it is most important to understand and assess the negative implications of patent hold-up on innovation.

\subsection{Procedural Framework for Licensing Negotiations}

While confirming the general applicability of Art. 102 TFEU to requests for prohibitory injunctions by SEP holders, the CJEU in Huawei also stressed that an SEP holder would not breach this provision as long as it fulfils certain procedural requirements. Thereby, the CJEU utilised EU competition law as a legal basis for designing a framework for bilateral FRAND negotiation processes.

Basically, the CJEU established the following consecutive rules of conduct. First, prior to bringing an action for infringement, the SEP holder has to alert the alleged infringer of the infringement. It is then for the alleged infringer to express its willingness to conclude a licensing agreement on FRAND terms. ${ }^{74}$ Secondly, the SEP holder has to present a specific written offer for a FRAND-compliant licence to which the alleged infringer has to diligently respond, eventually with a specific, written FRAND-compliant counteroffer. ${ }^{75}$ Non-compliance with these obligations would have far-reaching consequences for the SEP holder and the standard implementer as the former would be confronted with competition law liability or the latter with a prohibitory injunction. In the aftermath of Huawei, national courts have gradually addressed a considerable number of the manifold questions left open by the CJEU, thereby contributing to make this general framework operational. ${ }^{76}$ Still,

\footnotetext{
$\overline{74}$ CJEU, Case C-170/13, Huawei Technologies (16 July 2015) EU:C:2015:477, paras. 61 and 63.

75 Ibid., paras. 63 and 65-66.

${ }^{76}$ For a very comprehensive overview of relevant German court decisions see Picht (2018).
} 
numerous issues remain unsettled and different ones will arise as new lawsuits reach the courts. In this context, IoT licensing disputes will certainly be a major source for novel questions.

As pointed out above, ${ }^{77}$ the IoT differs from the more traditional telecommunications sector in several aspects. An increasing number of actors coming from the most diverse industry sectors will in the future be in need of network connectivity. Many of them will be alien to the ICT sector and, as the European Commission remarks in its Communication, be neither familiar with standardised connectivity technologies nor with the licensing of SEPs. ${ }^{78}$ Moreover, connectivity will not be the primary function of IoT devices, but the basis for a wide array of complex uses. These particular features of the IoT need to be taken into account when assessing whether the parties to a licensing dispute have complied with their procedural obligations.

In Huawei, the CJEU was markedly sensitive to the information problems confronted by standard implementers. Thus, it took account of the fact that telecommunications standards are typically controlled by a large number of SEPs of whose existence the alleged infringer may not be aware for deducing the SEP holder's obligation to provide it with prior notice of the infringement. ${ }^{79}$ Furthermore, the CJEU also noted that SEP holders may commonly hold more information related to the standard and relevant for the conclusion of a licensing agreement, and are thus better placed to present an initial licence offer. ${ }^{80}$ National courts have likewise emphasised the importance of providing the standard implementer with sufficient information to enable it first to assess the likelihood of an infringement, and secondly to adequately evaluate the FRAND-conformity of the SEP holder's offer and, if opportune, to come back with an analogous counteroffer. $^{81}$ The informational needs of standard implementers are greater the less acquainted they are with the relevant technologies. As argued, this will be the case for many companies offering IoT products and services. In addition, a large number of them will be small and medium-sized enterprises and start-ups lacking the necessary expertise and financial means to afford the costs associated with the provision of the pertinent information and generally with the licensing of SEPs. ${ }^{82}$ Courts should carefully take these factors into consideration when assessing whether the SEP holder's licensing offer is sufficiently concrete and specific and whether the implementer has "diligently" responded to it. ${ }^{83}$

\footnotetext{
77 See Sect. 2.1 above.

78 European Commission (2017a), pp. 2 and 3.

79 CJEU, Case C-170/13, Huawei Technologies (16 July 2015) EU:C:2015:477, para. 62.

${ }^{80}$ Ibid., para. 64.

81 See e.g. Düsseldorf Court of Appeals, order of 17 November 2016, Case I-15 U 66/15, paras. 24 et seq. With regard to the information to be provided in the notice on the purported infringement see Mannheim District Court (Landgericht Mannheim), order of 19 January 2016, Case 7 O 66/15, para. 73.

82 Stressing this point Tsilikas and Tapia (2017), pp. 175 et seq. (also providing recommendations to enable the participation of SMEs in ICT standardisation, both in their role as contributors and implementers).

83 In this context, the European Commission points out that there is a probable trade-off between the time considered as reasonable for responding to the offer and the detail and quality of the information provided in the SEP holder's initial offer, see European Commission (2017a), p. 10.
} 
Yet, IoT licensing does not only pose challenges for standard implementers. Technology owners too will face new kinds of users carrying out very distinct business models and implementing the standard in very different products and services. It is at least arguable whether they will always be in a position to perfectly appraise an implementer's specific circumstances when designing their FRAND offers. ${ }^{84}$ Again, courts should be sensitive to this fact and balance in each individual case the informational gaps that both SEP holders and technology users are confronted with.

Moreover, as compared to the classical SEP conflicts of the mobile phone environment, the implementer's products and business models as well as the different purposes for which telecommunications are used in the IoT sphere will differ enormously. This cautions against rapid conclusions that an SEP holder's offer does not conform with the non-discrimination element of FRAND only because a patent holder tries to charge a higher royalty rate. ${ }^{85}$ Indeed, the question of FRAND compliance already arises as part of the assessment of whether the licensing parties have fulfilled their procedural duties. In this context, and in contrast to traditional telecommunications applications, it has to be noted again that connectivity is not the main function of IoT devices, but just the base for more complex products and services. The extent to which this diversity can be reflected in the royalties SEP owners claim for their connectivity technologies will surely have to be among the most debated issues. Yet whether FRAND should oblige patent holders to charge uniform rates for all use cases or whether, on the contrary, they should be allowed to differentiate, ${ }^{86}$ goes beyond what this article aims to discuss.

\section{Conclusion}

As the IoT advances, connectivity-related technologies and standards enabling interoperability in this field will be crucial to develop a wide array of innovative data-related products and services. Network connectivity will be increasingly needed by a large number of market players in just about every economic sector. Moreover, uses for connectivity in the IoT context will be extremely varied and will substantially differ from traditional voice and data services. The economic potential that the IoT offers together with its very specific and varied connectivity needs has fostered the development of multiple connectivity technologies. IoT connectivity markets are currently highly dynamic. Even though some market consolidation will occur in the future, alternative connectivity technologies will continue to exist. In this sense, IoT connectivity markets differ from the markets for mobile telephony where players are largely locked into a small number of wireless and pathdependent telecommunications standards. Surely, for some IoT applications, the

\footnotetext{
${ }^{84}$ Making this point but not in the specific context of IoT licensing negotiations Picht (2016), p. 372.

85 In this sense too European Commission (2017a), p. 7.

${ }^{86}$ For example, the licensing platform AVANCI justifies the need to take different factors into account for setting their different flat-rate royalty rates, namely the need for wide area connectivity and mobility, the frequency of use as well as the required bandwidth, see AVANCI (2016), pp. 7 et seq. On the other hand see Fair Standards Alliance (Fair Standard Alliance 2016), p. 2.
} 
technology market will to a large extent resemble that in the smartphone sector. For a large part of IoT application areas, however, connectivity technology markets will be relatively competitive.

This circumstance will certainly constrain the ability of SEP holders to leverage on the standard essentiality of their patents. Hold-up scenarios may thus be less common in the IoT than presently feared. Yet lock-in situations may nevertheless arise for single implementers. In these cases and in those where an SEP holder is not exposed to competition by substitute technologies, EU competition law and Art. 102 TFEU in particular, will still be needed to control the SEP holder's behaviour.

In this context, the principles and framework set by the CJEU in its Huawei judgment are in need of some modifications to adequately respond to the particularities of future IoT disputes. At the outset, competition agencies and courts will have to cautiously consider the relationship between SEP ownership and market dominance. Far from being presumed, the existence of a dominant position on the part of an SEP holder will need to be carefully assessed on a case-by-case basis. Major shortcomings arise from the CJEU's leverage-based theory of exclusion applied in Huawei, which could be read as limiting the application of Art. 102 TFEU to vertically integrated SEP holders who compete with implementers in downstream markets. In the IoT sphere, SEP conflicts will increasingly arise between non-practicing entities and implementers alien to the ICT sector. Still, an application of Art. 102 TFEU is justified if one takes into account the need to protect dynamic competition in the very innovative IoT context. In contrast, the general procedural framework for licensing negotiations devised by the CJEU in Huawei is in principle flexible enough to account for the specificities of IoT licensing. National courts and competition authorities will nonetheless be challenged by the task to make it fully operational for the novel and complex IoT environment. For this environment, defining the criteria for FRAND-compliance will become an even more challenging task.

Acknowledgements Open access funding provided by the Max Planck Society.

Open Access This article is distributed under the terms of the Creative Commons Attribution 4.0 International License (http://creativecommons.org/licenses/by/4.0/), which permits unrestricted use, distribution, and reproduction in any medium, provided you give appropriate credit to the original author(s) and the source, provide a link to the Creative Commons license, and indicate if changes were made.

\section{References}

ABI Research (2018) Press Release - NB-IoT, CAT-M, Sigfox and LoRa battle for dominance drives global LPWA network connections to pass 1 billion by 2023, 11 June 2018. https://www. abiresearch.com/press/nb-iot-cat-m-sigfox-and-lora-battle-dominance-drives-global-lpwa-networkconnections-pass-1-billion-2023/. Accessed 15 Oct 2018

Alsen D, Patel M, Shangkuan J (2017) The future of connectivity: enabling the Internet of Things. https:// www.mckinsey.com/featured-insights/internet-of-things/our-insights/the-future-of-connectivityenabling-the-internet-of-things. Accessed 15 Oct 2018 
AVANCI (2016) Accelerating IoT connectivity. http://avanci.com/wp-content/uploads/2017/01/2016Avanci-WP-Final-_-Jan-24.pdf. Accessed 15 Oct 2018

Body of European Regulators for Electronic Communications (BEREC) (2016) Report - Enabling the Internet of Things. BoR 16:39

Drexl J (2011) Intellectual property in competition: how to promote dynamic competition as a goal. In: Drexl J, Grimes W, Jones C, Peritz R, Swaine E (eds) More common ground for international competition law? Edward Elgar, Cheltenham, pp 210-229

Drexl J (2012) Anti-competitive stumbling stones on the way to a cleaner world: protecting competition in innovation without a market. JCLE 8:507-542

European Commission (2017a) Communication to the European Parliament, the Council and the European Economic and Social Committee, setting out the EU approach to Standard Essential Patents, COM(2017) 712 final, 29 November 2017

European Commission (2017b) Cross-cutting business models for IoT - Final report. https://ec.europa.eu/ digital-single-market/sites/digital-agenda/files/newsroom/capture3_30153.jpg. Accessed 15 Oct 2018

European Commission (2018) Communication to the European Parliament, the Council and the European Economic and Social Committee, On the road to automated mobility: An EU strategy for mobility in the future, COM (2018) 283 final, 17 May 2018

Fair Standard Alliance (2016) Application-dependent SEP licensing. https://fair-standards.org/wpcontent/uploads/2016/09/FSA-Application-Dependent-Licensing-Paper.pdf. Accessed 15 Oct 2018

First H (2017) Exploitative abuses of intellectual property rights. In: Blair R, Sokol D (eds) The Cambridge handbook of antitrust, intellectual property, and high tech. Cambridge University Press, Cambridge, pp 222-244

GSMA (2016) 3GPP low power wide area technologies - white paper. https://www.gsma.com/iot/wpcontent/uploads/2016/10/3GPP-Low-Power-Wide-Area-Technologies-GSMA-White-Paper.pdf. Accessed 15 Oct 2018

GSMA (2018) Mobile IoT in the 5G future - NB-IoT and LTE-M in the context of 5G. https://www. gsma.com/iot/wp-content/uploads/2018/05/GSMA-5G-Mobile-IoT.pdf. Accessed 15 Oct 2018

Huang S (2018) China will lead the world in NB-IoT, which will benefit Chinese vendors and the ecosystems worldwide. http://www.analysysmason.com/Research/Content/Comments/China-IoTbenefits-RDME0-RDRP0/\#18\%20January\%202018. Accessed 15 Oct 2018

Kathuria V and Lai JC (2018) Validity of non-disclosure agreements in SEP licensing, EIPR 40 (forthcoming). Also available at https://papers.ssrn.com/sol3/papers.cfm?abstract_id=3092219. Accessed 15 Oct 2018

Lethaby N (2017) Wireless connectivity for the Internet of Things: one size does not fit all. http://www.ti. com/lit/wp/swry010a/swry010a.pdf. Accessed 15 Oct 2018

McKinsey Global Institute (2015) The Internet of Things: mapping the value beyond the hype. https:// www.mckinsey.com/ /media/McKinsey/Business\%20Functions/McKinsey\%20Digital/Our\% 20Insights/The\%20Internet\%20of\%20Things\%20The\%20value\%20of\%20digitizing\%20the\% 20physical\%20world/The-Internet-of-things-Mapping-the-value-beyond-the-hype.ashx. Accessed 15 Oct 2018

Northstream (2016) Connectivity technologies for IoT. http://northstream.se/northstreamwp/wp-content/ uploads/2017/01/Northstream-White-Paper-Connectivity-Technologies-for-IoT.pdf. Accessed 15 Oct 2018

OECD (2017) Competition issues in aftermarkets - note from the European Union, DAF/COMP/ WD(2017) 2, 13 June 2017

OneM2M (2017) White paper - Boost LPWA revenue through oneM2M, December 2017. http://www. onem2m.org/images/files/oneM2M_WhitePaper_BoostLPWARevenueThroughoneM2M.pdf. Accessed 15 Oct 2018

Pepe S, Post K, Shapiro L (2018) Internet of Things: next patent war zone. https://biglawbusiness.com/ internet-of-things-next-patent-war-zone/. Accessed 15 Oct 2018

Petit N (2017) EU competition law analysis of FRAND disputes. In: Contreras J (ed) The Cambridge handbook of technical standardization law - competition, antitrust, and patents. Cambridge University Press, Cambridge, pp 290-305

Picht P (2016) The ECJ rules on standard-essential patents: thoughts and issues post-Huawei. ECLR $37: 365-375$

Picht P (2017) Unwired Planet $v$ Huawei: a seminal SEP/FRAND decision from the UK. JIPLP 12:867-880 
Picht P (2018) "FRAND war 2.0" - Rechtsprechung im Anschluss and die Huawei/ZTE-Entscheidung des EuGH, Teil 1. WuW: 234-241; Teil 2. WuW: 300-309

Rose K, Eldridge S, Chapin L (2015) The Internet of Things: an overview. https://www.internetsociety. org/wp-content/uploads/2017/08/ISOC-IoT-Overview-20151221-en.pdf. Accessed 15 Oct 2018

Ryberg T (2018) The global M2M/IoT communications market, 3rd edn. Berg Insight, Gothenburg

Tsilikas H (2017) Huawei v. ZTE in context - EU competition policy and collaborative standardization in wireless telecommunications. IIC 48:151-178

Tsilikas H, Tapia C (2017) SMEs and standard essential patents: licensing efficiently in the Internet of Things. Les Nouvelles LII:170-176

World Economic Forum (2018) Internet of Things - guidelines for sustainability. http://www3.weforum. org/docs/IoTGuidelinesforSustainability.pdf. Accessed 15 October 2018

Yamaguchi A (2018) Does the Internet of Things need a new legal framework for standard essential patents? Observations from a comparative perspective, Master Thesis, Munich Intellectual Property Law Center (MIPLC, yet to be published) 